\title{
Lexis
}

Journal in English Lexicology

$6 \mid 2011$

Diminutives and Augmentatives in the Languages of the World

\section{When Small Is Many in the Event Domain}

\section{Lucia M. Tovena}

\section{(2) OpenEdition \\ Journals}

Electronic version

URL: http://journals.openedition.org/lexis/414

DOI: 10.4000/lexis.414

ISSN: 1951-6215

Publisher

Université Jean Moulin - Lyon 3

\section{Electronic reference}

Lucia M. Tovena, «When Small Is Many in the Event Domain », Lexis [Online], 6 | 2011, Online since 27 March 2011, connection on 19 April 2019. URL : http://journals.openedition.org/lexis/414 ; DOI :

10.4000/lexis.414

\section{(c) $\oplus \Theta \Theta$}

Lexis is licensed under a Creative Commons Attribution-NonCommercial-NoDerivatives 4.0 International License. 


\title{
When Small Is Many in the Event Domain
}

Lucia M. Tovena ${ }^{1}$

\begin{abstract}
This paper pursues the idea that event-internal pluractional verbs are morphologically complex forms that describe non-canonical events and denote in the domain of events constituted by pluralities of phases [Tovena 2010b]. Non-canonicity is understood in comparative terms with respect to the description of the events provided by the corresponding simplex verb forms. The leading question is what is the source of the multiplicative meaning component in verb forms such as tagliuzzare and tossicchiare in Italian, and it is answered by arguing that it arises from the use of diminutive morphology specifically to build verb forms that describe modified events. Parallelisms with the nominal domain strengthen the case for a characterisation of the word formation process as involving diminutive morphology. It is also shown that the type of modification of an event description allowed by forming pluractional verbs is generally more complex that by simple adverbial or PP adjunction, as it involves at least two dimensions of the event. Furthermore, languages may use morphological distinctions to mark different binary oppositions within Cusic's three level system.
\end{abstract}

Keywords: diminutive suffixes - pluractionality - evaluative elements - verb formation - Italian French - Emerillon

$* * *$

\section{Résumé}

Dans cet article, nous développons l'idée que les verbes pluriactionnels à pluralité interne sont des formes morphologiquement complexes qui décrivent des événements non-canoniques et qui dénotent dans le domaine des événements constitués par des pluralités de phases [Tovena 2010b]. La non-canonicité se comprend en termes comparatifs par rapport à la description des événements fournie par les formes verbales simples correspondantes.

Notre point de départ est la question de savoir quelle est la source de la composante de sens multiplicative que l'on retrouve dans des verbes tels que tagliuzzare et tossicchiare de l'italien. Notre réponse consiste à montrer qu'une telle multiplicité découle de l'emploi de la morphologie diminutive pour former des verbes qui décrivent des événements modifiés. Nous mettons au jour une forme de parallélisme entre le domaine nominal et le domaine verbal afin de renforcer notre hypothèse qu'il s'agit bien de morphologie diminutive. Nous montrons que la modification de l'événement obtenue par ce processus de formation de verbes (déverbaux ainsi que dénominaux) est toujours au moins double, alors qu'une modification par le truchement d'un adverbe ou d'un groupe prépositionnel ne concerne qu'une dimension à la fois.

Mots-clés: morphologie diminutive - pluriactionnalité - éléments évaluatifs - formation de verbes - italien - français - émérillon

\footnotetext{
${ }^{1}$ Université Paris 7, France: tovena@ linguist.jussieu.fr
} 


\section{Introduction}

The Italian pairs of verbs in (1) suggest that diminutive suffixes provide a morphological device languages can exploit to create so-called frequentative verbs, i.e. forms whose meaning include diminutive and multiplicative components.
a. tagliare cut tagliuzzare 'cut into [*one/many] small pieces'
b. tossire 'cough (once or many times), 2
tossicchiare 'give [*one/many] small coughs'

The multiplicative meaning component does not show up in nominal forms modified by the same affixes, cf. (2).
a. filuzzosing $=$ 'one $[$ single $/ *$ multiple $]$ thin thread' filuzziplu $=$ 'several [single/*multiple] thin threads'
b. governicchiosing $=$ 'one [single/*multiple] government of little value' governicchiplu $=$ 'several [single/*multiple] governments of little value'

These data prompt several questions. What is the relation between the diminutive and the multiplicative meaning components? Is it the base or the suffix that contributes the multiplicative component to the overall verb meaning? How is it done? Is it really diminutive morphology? We propose that all these questions point at relevant aspects of a single derivational process of verb formation whereby diminutive suffixes contribute to creating new verbs that denote singular complex-like events by overtly marking that the parts of the entity whose structure should be homomorphic to the structure of the event are not properly assembled. This is because the properties of the (semantic) thematic role that links such an entity to the event are modified in a way that reduces cohesion [Tovena 2010c]. The type of this complex-like event is the same as what event-internal pluractional verbs are meant to describe, according to the characterisation proposed by Cusic [1981].

The structure of the paper is as follows. In section 2, we start by providing the intuition regarding the type of situation that can be described by verbs of the group exemplified in (1), and then recall the main properties of pluractional verbs and point out some issues in the characterisation of the group under examination. The section concludes with the presentation of the main features of the semantic analysis of event internal pluractionality that we adopt. Its main assumption is that the parts of the event remain visible because they are not properly added up to form a whole and this results in the perception of a predicate applied to a singular entity by distributing it over its parts. We are then ready, in section 3, to pick up the issue of the source of the multiplicative meaning component pointed at above. This multiplicative component is not intrinsic in diminutive morphology, we argue, but surfaces as a result of using diminutives to output verbal forms. Diminutive suffixes can be associated with different semantic operations that are sketched out in analogy with what is generally assumed for adjectives. The use of diminutive suffixes in pluractional verb formation is closer to the process of creation of a new property of events than to modification of a word's denotation via a restriction of the property expressed by the base. Repeated parallelisms between verbal and nominal domains give structure to the section. Last, section 4 discusses some general

\footnotetext{
2 This is a semelfactive verb, thus it has a reading corresponding to performing the action once, and another reading corresponding to performing a sequence of acts.
} 
issues concerning expressions that realise pluractionality. A crucial difference between morphologically complex verbs that express event-internal plurality and adverbially modified verbs is that the former always express properties of events modified along at least two dimensions, i.e. increase in frequency and decrease of one or more other dimensions. Therefore, word formation of pluractional verbs by evaluative morphological marking gets direct semantic justification. However, the process does not appear to be fully active in the languages under examination. Finally, we observe that morphological complexity need not be seen as the proper of a specific type of pluractionality. The two cases presented suggest that the number opposition between event-internal plurality and event-external ones - i.e. involving events or occasions - proposed by Cusic, is not the only option. Section 5 sums up the main points.

\section{Pluractionality}

\subsection{The intuition}

Consider the Italian sentences in (3). The event described in (3a) is not shortened w.r.t. (3b), nor is the apple shrunk, rather the diminutive modification concerns the property describing the event (Aktionsart), and more specifically the way the direct object is used to instantiate a thematic role.

\footnotetext{
a. Mangiucchia la mela

S/he is eating at/eating on and off the apple

b. Mangia la mela

$\mathrm{S} / \mathrm{he}$ is eating the apple
}

The sentence in (3b) describes the eating of the apple by an unspecified agent and does not provide any special information about it. Abstracting away from the peculiarities of each individual event, the hearer is entitled to infer that the sentence is about a normal state of affairs. On the contrary, sentence (3a) specifies that the eating of the apple does not take place in the standard way. Rather the action is described as being performed with a kind of reduced engagement by the agent that shows in smaller bites and lack of continuity, and the culmination is less easily inferred.

The difference between these sentences can be summarised by saying that in $(3 b)$ the argument that stands in the Patient/Theme relation with the event, i.e. the apple, is perceived as if it were instantiated 'by instalments' that are not referentially accessible-i.e. disconnected little anonymous parts of the apple undergo the eating. This is reflected in the emerging of the interpretive effect of multiplication. The semantic effect is double insofar as the event appears as being fragmented into multiple subevents and each of them has a reduced Patient/Theme.

\subsection{Verb plurality}

We propose that in (3a), diminutive morphology marks event-internal pluractionality [Tovena 2007, 2010b]. Pluractionality [Dressler 1968; Newman 1980; Cusic 1981] is concerned with the morphological expression of number inherent to the verb, different from number agreement. Verbal plurality is often understood as plurality of events that may arise from various sources, e.g. events taking place at subsequent times or in distinct places. These 
sources of multiplicity could be seen as the key in a form of distribution where the event predicate would be the share.

Languages possess a variety of morphosyntactic tools to express different semantic forms of repetition of (sub-)events, e.g. affixation, full or partial reduplication, or gemination. By extension, cases where plural event information is conveyed by adverbials have also been considered to be part of the phenomenon in the literature. A few examples, mainly from the Romance set, are provided in (4).
a. prefix, e.g. re-: reinstantiation of a predicate of event, e.g. rediscover, Fr. se remarier 'get married again'
b. adverbials, e.g. Fr. encore 'still/yet/again': reinstantiation within an information structure, Fr. de nouveau 'afresh' [Tovena and Donazzan 2008]
c. word reduplication: reinstantiation with intensification, e.g. It. fuggi fuggi 'run away' [Thornton 2007]
d. suffixation, e.g. evaluative suffixes: repeated partial instantiation, getting away from the prototype, example (3a)

Cusic [1981] has proposed that verb plurality concerns several conceptual levels and has defined a hierarchical arrangement of bounded units in three levels of structure, namely occasions, events, and phases. Pluralisation is possible at each level, indicating 'more than one isomorphic bounded unit of that level' [Cusic 1981: 69]. He then reorganises the levels into two main types of pluralities. The first type, called event-external plurality, is a plurality constituted by units of the event or superevent type, i.e. Cusic's occasions. Time, locations or participants can be seen as the key for a form of distribution. The second type is event internal plurality, which applies to cases where there are forms of multiplicity that have a source that does not impact on the singularity of the event, and the events involve single participants. When repetition takes place within the boundary of one event, phases are the relevant temporal units, i.e. entities of a subevent type. More Romance examples of the eventinternal pluractional type are provided in (5):
a. Italian mordicchiare 'nibble several times', dormicchiare 'drowse', piovigginare 'drizzle'
b. French mordiller 'nibble several times', sautiller 'hop', neigeoter 'snow a little'
c. Spanish mordisquear 'nibble several times', chupetear 'suck a little and several times'

Cusic does not take an explicit ontological commitment with respect to the original levels of his hierarchy. In our understanding of his words, by choosing to reorganise them into two groups, where events and occasions go together, and by giving a central role to events at least in his terminological choices, he may be seen to suggest that events are the main level. We endorse this position. He may also be taken to suggest that the bipartition resulting from setting the number opposition between event-internal plurality and event-external plurality holds across languages as the only option. We will see in section 4.3 that Emerillon, a language of the Tupi-Guarani family, and Standard Arabic may offer counterexamples by conveying number opposition at a higher level of the hierarchy, namely between phases or events vs. occasions. 


\subsection{Event-internal plurality}

Two main subtypes of event-internal plurality have been identified by Cusic. The first, that chiefly concerns this paper, is the decrease type, seen in (5) and that is also present in English, e.g. twinkle. The second is the increase type, and is illustrated by the second form (wazn) of verbs in Arabic, e.g. kassara 'smash', darraba 'beat up'. The analysis of forms of event-internal pluractional verbs of the decrease type raises several questions, because they can be traced to different sources. On the one hand, the morphological status of specific components can be a matter of debate. For instance, in general derived verbs in Italian and French are formed by prefixation, not by suffixation, but in this paperwe explore the hypothesis that diminutive suffixes are involved in the formation of these verbs, not simple submorphs. Note that, it is often assumed that pluractional verbs involve a step of derivational morphology, whereas number marking in the nominal domain traditionally belongs to inflectional morphology. On the other hand, the semantic nature of the components that are invoked is not homogeneous across languages. Cusic says that the English verbs derive from old iterative affixes -er, -le, quoting $O E D$. Romance forms might derive from diminutive affixes, as we propose at least for Italian. This variety is a challenge for compositional semantics, since it forces semanticists to target one result, i.e. the characterisation of the diminutive type of pluractionality, by going up partially distinct paths, i.e. the iterative or diminutive content of the affixes. Event-internal pluractional verbs have been analysed by Tovena [2007, 2010a] as denoting composite single events that result from distributing the predicate on the fragments of one participant. This semantic analysis takes up the idea that distributivity is a form of plurality. The main claim is that the properties of event internal pluractionality can be captured by means of two specific operations of semantic decomposition in the characterisation of the singular event. First, an event described by a pluractional verb is a single event decomposed into a plurality of phases, i.e. the event is locally fragmented into a plurality. Second, in this single event at least one participant is decomposed into parts, and phases reflect the application of the predicate to the parts of the participant demoted to a sum.

Key elements of this formal analysis are the constraint that the complex internal structure of the single event described by the pluractional verb is a groupified plurality of phases. Plurality is obtained by the joint effect of the plural operator ' $*$ ' [Link 1983] applied to the event property and the application of the grinding operator [Landman 1991, 2000] to the atomic affected participant. The cells of a cover weaker than the one having the atom as its unique cell, are used as the parts over which the predicate is distributed. Next, the plurality of phases is given the status of unit at event level by an operation of groupification [Landman 2000]. The step of groupification is lexicalised, as the verb does not make phases accessible. Example (6) illustrates the fact that phases cannot be counted, as it can only be understood as saying that there are two events of nibbling, not two little-bitings making up one nibbling. The short dialogue in (7) shows that the duration of events can be compared, but not via counting individual phases. The affected argument usually is the Patient/Theme in transitive verbs. It is fragmented locally and the parts are not accessible at discourse referent level, hence phases weakly exist as a reflection of the cells of a cover. The only accessible elements are the variables for the event and the participants. This accounts for the connectedness of event-internal plurals noted by Cusic.

(6) Daniele ha mordicchiato la matita due volte

Daniele nibbled the pencil two times 

A: Daniele ha mordicchiato la matita più di Maria
Daniele nibbled the pencil more (= longer, $\neq$ more bitings) than Maria
$\mathrm{B}$ : * No, perché lei è più veloce.
No, because she is faster

Tovena [2010c] makes clear that fragmenting means crossing out the homomorphism between the mereological structures of (one or more) entities whose properties provide scales and the event. In the canonical case, the unfolding of the event ismeasured by adjacent isomorphic transitions of the theme along a scale related to the event by Krifka's [1998] Movement Relation. On the other hand, in event-internal pluractional verbs, the correlation between a dynamic predicate and a form of gradability is disrupted. The event description loses strict incrementality measurable on an external scale, without losing the possibility of comprisingmultiple changes. Duration and dynamicity are preserved, but 'later in time' does not correlate with a higher degree on a scale, as expected in the canonical case. There is an increment of energy consumed while duration increases, i.e. it is an activity and not a state, but no specific unit or stage of the event (homogeneously identified) can be made correspond to this increment (in any explicit way). Apparently no scale is traversed for describing the energy consumed. For the sake of this paper, it is enough to assume that the correlation is disrupted because the structure associated to the theme is not properly constructed out of the parts. The faulty way the parts are put together when computing the measure of a dimension relevant to the whole event may be the source of the interpretations of the diminutive and augmentative subtypes mentioned above.

\section{Evaluative morphology and pluractional verbs}

In this section, some consequences of hypothesising that the exponent found in pluractional verbs is related to evaluative morphology will be explored.

\subsection{Pros and cons of invoking evaluative morphology}

Invoking evaluativemorphologymakes less surprising the variety of forms found among pluractional verbs in Italian and French. In French, evaluative morphology is not very productive. Facts are clearer in Italian, a language whose productive evaluative suffixes, e.g. -in, -ett, -ell, -uzz, form a large collection.

A possible drawback of calling into play this type of morphology is its problematic status. Indeed, evaluative morphology does not fit nicely in the inflectional vs derivational partition of morphology, according to several scholars. Scalise [1984]; Bauer [2004] have underscored difficulties in its characterisation, and Scalise has explicitly excluded diminutives from the derivational system. Stump [1993], on the contrary, has argued against granting it special status. We will not summarise the debate, but we recall that all these authors agree on the property of category preserving of evaluative affixation. For the topic of this paper, it is worth noting that analysing the formation of pluractional verbs in terms of evaluative suffixation would potentially add to the complexity of the debate, because pluractional verbswould offer exceptions to the property of never changing the syntactic category of the base, see the Italian forms in (8): 


\section{a. mordicchiare-mordere ${ }_{\mathrm{V}}$ 'bite'}

b. punteggiare-punto ' $_{\mathrm{N}}$ dot'

One could try to show that nothing special has to be added for pluractional verbs concerning this issue of whether the syntactic category of the base is always preserved by evaluative morphology. This line of argumentation could rest on at least three points. First, a sort of partial answer to the issue of potential exceptions to the preservation property comes from diachronic facts. The issue is moot when the step of verb formation is subsequent to evaluative modification. This is the case in denominal verbs for which verbalization is the last step, e.g. French somnoler 'drowse' comes from the root of late Latin somnolentia, or Italian sonnecchiare 'drowse' from Latin somniculus, which is a diminutive of somnus. It is moot also in cases where the two steps are synchronous, e.g. macchiettare 'dot'. Second, form similarity is another possible explanation, as illustrated by the possibility that two verb forms have been crossed, e.g. French cafouiller 'shamble' from cacher* and fouiller*. This is the etymology proposed by CNRTL. Alternatively, cafouiller has Picard origin from fouiller and a pejorative prefix $\mathrm{Ca}$-, according to the dictionary Petit Robert. In either case, we would have derivation without evaluative suffixation. Third, there are also cases where there is only a step of verb formation and no evaluative modification has ever taken place. For example, the French verb pianoter 'type on a keyboard' is derived from the noun piano and means 'tinkle away' when it is a piano keyboard. An epenthetic - $t$, together with the ending of the base, seems to have been reanalysed as a latent consonant belonging to the affix -ot, interpreted as one of the marks of the pluractional group of verbs, possibly as the diminutive affix. The pluractional interpretation has been available from the start. Verbs for playing musical instruments in French follow an altogether different path as a regular process.

Alternatively, the issue of potential exceptions to the property of category preserving can be tackled by assuming that different answers correlate with different semantic processes, that is such a property characterises the behaviour of diminutive suffixes in their working as degree/quantitymodifiers, but not in their working as pluractional suffixes, which will be set on the same side as quality modifiers. In order to explore this tack, we start from observations concerning the nominal domain.

\subsection{Semantic operations and category preservation in nominal evaluative suffixation}

The first point we want to make in this section concerns the variety of semantic operations that can be performed by adding evaluative suffixes. Diminutive suffixes exhibit a double behaviour in the nominal domain, as it can be inferred from previous descriptions, cf. Dressler and Merlini Barbaresi [1994], Jurafsky [1996] among others. On the one hand, diminutives may say something about the referent of the NP by restricting the property predicated of it, e.g. in Italian an entity that is a librino is a libro 'book' and is small, i.e. the derived form denotes in a subset of the original denotation domain.

On the other hand, diminutives may help to form a new property whose denotation can be an altogether different set of entities, e.g. the denotation of It. fiorino 'florin' is a set of coins and is not a set of little flowers. The historical link between the two words is a different, albeit important, issue. It concerns the reason why a language has used a given element (here flower) to create a new word (here the name of a coin), not the possibility itself.

It is worth underscoring that this second behaviour corresponds to a lexicalised derivative step. More importantly, it does not always satisfy the property of category preservation. Nouns of small instruments offer another relevant example of suffixation accompanied by 
category change, e.g. scaldare $_{\mathrm{V}}$ - scaldino $_{\mathrm{N}}$ 'warm, [hand/bed] - warmer' or accendere $_{\mathrm{V}}$ accendino $_{\mathrm{N}}$ 'switch on, lighter' [Lo Duca 2004; Merlini Barbaresi 2004]. On the contrary, the first behaviour is strictly category preserving.

The second point worth emphasising is that this variety of semantic operations associated with evaluative suffixation is strongly reminiscent of the debate on the semantic characterisation of adjectives. Syntactically, adjectives can enter two main types of constructions, namely they can be used as prenominal or attributive modifiers, as in (9a), or be used predicatively, as in $(9 b)$ :

a. Fido is a brown/big/good dog

b. Fido is brown/big/good

Semantically, they may denote properties, e.g. the property of being brown, and give rise to intersective interpretations [Montague 1974], e.g. Fido is a member of the intersection between the set of brown things and the set of dogs. Set intersection is formally represented by logical conjunction, i.e. Fido is brown and is a dog. Adjectives may also give rise to subsective interpretations [Montague 1974], e.g. Fido may be a big dog but not be considered to be big in more general terms. In this case, the property denoted by the noun is entailed, and the adjective carves out a subset denoted by the property big dog. No independent 'bigness' property is assumed and no intersection is computed. The adjective is formally analysed as a functor applying to the noun to return a new property. This is typically the case of degree or measure adjectives. It is open to debate whether gradable adjectives are never intersective, i.e. whether they can sometimes be analysed as denoting properties of individuals, which are functions from entities to truth values and are represented as semantic predicates of type $<\mathrm{e}, \mathrm{t}\rangle$, or are functions from properties to properties, i.e. are semantic modifiers and get the semantic type $<<\mathrm{e}, \mathrm{t}>,<\mathrm{e}, \mathrm{t}>>$. We cannot do justice to the complexity of the debate on this important point in this paper. ${ }^{3}$ What is relevant for us is that (9b) can be interpreted as saying that Fido is big as a dog, i.e. with respect to the set of dogs as in (9a) and discussed above, but also that it is big with respect to a different class of comparison constituted by a set of entities relevant in the context. ${ }^{4}$ Finally, evaluative adjectives, like good, are interpreted relatively to the noun they modify, like degree adjectives. Like degree adjectives, they are not intersective modifiers, Luisa is a beautiful dancer does not entail Luisa is beautiful [Siegel, 1976]. They differ from degree adjectives insofar as their interpretation depends also on a given criterion, beside the comparison class. For instance, if Luisa is a good dancer, it is not enough for her to be the best of her poor quality classmates, she must be good according to a general standard of evaluation.

Going back to our discussion on the semantic processes that can be associated to diminutive suffixation, we can substantiate our initial distinction. Notice that diminutive suffixes would differ from gradable adjectives at least on the fact that their comparison class would always be overtly provided by the base they combine with. Like evaluative adjectives, they may be interpreted according to a standard, i.e. a librino is small or thin with respect to the usual size for books. The first behaviour identified at the beginning of this section is consistent with these points and corresponds to the subsective interpretation of adjectives. Conversely, the second behaviour corresponds to a case of non-intersective interpretation. The new property denoted by the suffixed noun may have only figurative or remote links with the denotation of the base noun. This conclusion is all the more plausible if we recall that when the adjective combines with the noun like a function with an argument, habitually the

\footnotetext{
${ }^{3}$ We refer the reader to Montague [1974] and Siegel [1976] for two classic diverging views.

${ }^{4}$ For instance, it can be a big pet when compared to a gold fish and still be a small dog.
} 
intension of the expressions is invoked. The natural conclusion is that derivational morphology typically affects the semantic type of linguistic expressions and is associated with semantic operations on intensions.

\subsection{Verbal evaluative morphology}

The same double behaviour found with respect to nominals is to be observed in the domain of events.

\subsubsection{Getting multiplication from verb modification}

Let us look at the two behaviours in reverse order, starting from the case where pluractional verbs fit in. Diminutives help to define a new property of events, e.g. we have seen that in example (3a) Gianni mangiucchia la mela, the existence of a single event is not questioned with respect to (3b) Gianni mangia la mela, the duration of the event is not affected nor the size of a participant, rather the diminutive modification concerns the progression of the event, the way the direct object gets used to instantiate a thematic role in the event. Whatever dimension can be used in the canonical realisation of the event in order to measure the incremental development of the event and can match its increased duration, it is no longer information available in the pluractional case.

This modification that takes into consideration the participants in an event is available for verbs but not for nouns and yields the interpretive effect of multiplication. The thematic role relates the whole entity 'apple' to the event, but the relation is instantiated 'by instalments' that are not organised in an ordered incremental structure. This has the effect of making the part-of structure visible and sort of 'multiplying' reduced local themes, which results in the diminutive type of the event-internal pluractional meaning of the verb. The verb category of the output is the crucial part of the derivational process, while the base can be an idealised form, existent or not, and verbal or not, e.g. what said for deverbal mangiucchiare applies for non-deverbal punteggiare. However, deverbal cases anchor the extension by analogy, which works under the hypothesis that there is a modified thematic grid.

In the literature on aspect, the link between the properties of the direct object NP and the aspectual properties of the VP has been explored in depth. As it can be expected, if pluractionality is an operation that records the modification of the canonical unfolding of an event, it should have aspectual consequences. Indeed, the direct object can no longer properly measure out the event [Dowty 1979; Tenny 1994; Krifka 1998], hence telicity is affected, cf. the possibility of modifying examples like (3a) with an adverbial of duration, whereas (3b) is modified by an adverbial of measure (10) :

a. Gianni ha mangiucchiato la mela per dieci minuti

Gianni has been eating at the apple for ten minutes

b. Gianni ha mangiato la mela in dieci minuti

Gianni has been eating at the apple in ten minutes

Diminutives can also work as modifiers that restrict the meaning like measure adjectives. This produces a subsective interpretation and corresponds to the first behaviour identified for noun modification above. For instance, 'speak a little a foreign language', e.g. English, can be expressed by adverbial modification (parlare un po' l'inglese) or by suffixation (parlicchiare l'inglese) in colloquial Italian. An analogous example is provided by colloquial French detestouiller 'dislike a bit'. This modification concerns one dimension of the description, 
whose measure is lowered. This point is very important for the characterisation of the class of verbs and we will come back to it. But for the issue we are discussing in this paragraph, what matters most from the semantic point of view is that the internal structure of the event is not altered. Its progression is is not affected, it is the total value of one dimension that is required to be low/below the standard. In the example in hand, the competence that is attested by the sample of English language produced by the speaker is claimed to be very limited. And from the morphological point of view, what matters is that this modification is not lexicalised, concerns deverbal verbs and thus is category preserving, and does not undergo the same aspectual constraints.

\subsubsection{A morphological regularity in conjugation class}

The hypothesis that diminutive morphology is involved in pluractional verb formation is supported also from evidence with respect to conjugation classes. Notice the contrast between the uniformity of the group of pluractional verbs in Italian and French, as they all belong to the first conjugation class (respectively -are and -er), and the variety of conjugations found among the corresponding non-pluractional forms, when they exist. This difference might seem unexpected, since derivation should not affect inflection. However, ifwe take amore inclusive look at the peculiarities of diminutive morphology, we can read this difference as representing precisely the verbal counterpart of the effect of inflection 'normalization' found with evaluative morphology in the nominal domain. Let's look at Italian, where it is easy to identify classes in inflectional morphology of nouns.

\section{Nominal domain}

Evaluative morphology in the nominal domain has the effect of converting all nouns into one single morphological class. Italian has three main inflectional classes for nouns, exemplified in (11):

\begin{tabular}{|c|c|c|}
\hline & Singular & Plural \\
\hline $\begin{array}{l}1 \text { masculine } \\
\text { feminine }\end{array}$ & $\begin{array}{l}\text { libr-o } \\
\text { favol-a } \\
\end{array}$ & $\begin{array}{ll}\text { libr-i } i & \text { 'book' } \\
\text { favol-e } & \text { 'fairy tale' }\end{array}$ \\
\hline $\begin{array}{l}2 \text { masculine } \\
\text { feminine }\end{array}$ & $\begin{array}{l}\text { poet-a } \\
\text { al-a }\end{array}$ & $\begin{array}{ll}\text { poet } i & \text { 'poet' } \\
\text { al- } a & \text { 'wing' }\end{array}$ \\
\hline $\begin{array}{l}3 \text { masculine } \\
\text { feminine }\end{array}$ & $\begin{array}{l}\text { dolor-e } \\
\text { nav-e }\end{array}$ & $\begin{array}{l}\text { dolor-i 'pain' } \\
n a v-i \text { 'ship' }\end{array}$ \\
\hline
\end{tabular}

Nouns from the three classes inflect all according to the most stable class, given as the first block in (11) and here called the first class, when they are modified by evaluative morphology [Merlini Barbaresi 2004]:

\begin{tabular}{|c|l|l|}
\hline & Singular & \multicolumn{1}{|c|}{ Plural } \\
\hline $\begin{array}{c}\text { masculine } \\
\text { feminine }\end{array}$ & $\begin{array}{l}\text { librin- } o \\
\text { favolett- } a\end{array}$ & $\begin{array}{l}\text { librin- } i \text { 'small book' } \\
\text { favol-e 'small fairy tale' }\end{array}$ \\
\hline masculine & poetin- $o$ & poetin- $i$ 'little poet' \\
feminine & alucci- $a$ & alucc-e 'small wing' \\
\hline masculine & dolorett- $o$ & dolorett- $i$ 'little pain' \\
feminine & navicell- $a$ & navicell-e 'little ship' \\
\hline
\end{tabular}




\section{Verbal domain}

The same effect of 'normalisation' is found in the verbal domain, where the first conjugation works as default class (numbers refer to the traditional classification of conjugation classes).

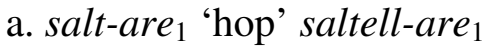
b. piov-ere 2 'rain' pioviggin-are 1
c. toss-ire ${ }_{3}$ 'cough' tossicchi-are 1

It can be hypothesized that the same holds for French, but the effect is obscured by the reduced productivity of evaluative derivation and the debatable existence of inflectional classes in the nominal domain.

\section{Expressing verbal plurality}

In this last section, we discuss some general issues concerning expressions that realise pluractionality. Diminutive pluractionals are perceived as describing a situation as noncanonical, so we start by considering what it means to lexically modify an event description. Subsequently, we will consider which type of number opposition can be expressed by morphological differences.

\subsection{Modifying an event description}

A situation described by an event-internal pluractional verb is presented as modified with respect to a canonical one, which can be viewed as setting the standard or constituting the prototype. Furthermore, verbs of the diminutive type are often perceived as colloquial and pejorative forms. Pluractionality of the diminutive type is not restricted to diminutive affixation across languages. The analysis pursued in this paper extends to languages that express diminution through morphological devices other than suffixation.

Let us first consider the non-canonical nature of the situation described. Adverbs and PPs are typical instances of constituents that help modifying an event description. The modification realised via a pluractional form semantically differs in a crucial way from what can be done by adverbs and PPs insofar as it concerns at least two dimensions of the description. It always involves increase in frequency and diminution along a different dimension, at least one and possibly more. Typical cases are a decrease in the portion of the entity affected (14a), the amount of will or energy required (14b), the linear length of the paths covered (14c), the output obtained (14d), the sound amplitude (14e):
a. mordicchiare 'nibble'
b. vivacchiare 'live from hand to mouth', saltellare 'hop'
c. gironzolare 'go around aimelessly'
d. piovigginare 'drizzle'
e. tossicchiare 'cough lightly and repeatedly'

Clear multiple dimension decrease is illustrated in (15): 
(15) leggiucchiare 'read for short time spans and with little attention, small parts of text', sonnecchiare 'drowse, sleep lightly and for short time spans'

Finally, the choice of the affected participant follows the schema according to which NPs are taken into account when evaluating Aktionsart ${ }^{5}$, e.g. telicity, or more generally the argument whose change is measured by a scale correlated to the progression of the event. It can be the hidden theme in verbs whose meaning is the coming into being of a metereological event, as in Fr. negeoter 'snow a little' and (14d). It can also be the internal object in intransitive verbs as in vivacchiare (14b).

Diminutive morphology helps us to capture the colloquial and pejorative flavour of the description. Expressing a biased assessment is what an evaluative form is expected to do. Expressing a shade of reduction is what diminutives should do.

\subsection{Frozen pluractionals}

Taking stock, we have provided several arguments for a semantic characterization of the class of verbs, and reasons for its morphological analysis. One could still wonder whether the pairing of modified-canonical description of a situation is the result of a derivational word formation step or, instead, it is a formal similarity with diminutives that triggers the search/hypothesis of matching simplex forms. Before we leave the matter, it is worth considering once more the strength of our arguments. As for Italian and French, it would be too weak to conclude that there is no unique morphological criterion that applies in all cases. It is true that beside good examples of simple-derived pairs such as French mordre vs. mordiller 'nibble', there are fewer but equally good counterexamples such as denominal pluractional pianoter. However, the fact that they have undergone retroanalysis from the start argues in favour of the perception of a morphosemantic correspondence rather than against it. As for semantics, there is a strong perception of semantic coherence in the class. Good examples are provided by forms such as French derived pluractional mordiller, spurious counterexamples are verbs like those in (16).

\section{a. Italian frammentare 'fragment', oscillare 'oscillate' \\ b. French fragmenter, osciller}

These cases are not relevant because do not fit in the semantic characterisation. Indeed, 'fragment' is a verb that describe a simple action whose result is to get the entity instantiating the object into pieces, but that is not composite itself. As for 'oscillate', it describes a composite action made up of subevents that somehow can be singled out because their order cannot be altered. No order can be imposed on the set of phases denoted by an event internal plural verb. Note that the cases in (16) are morphologically not relevant, since they are simplex forms. Note also that modification is possible in verbs describing repeated movements, cf. (17). In this case, the morphologically complex form tremolare adds a weaker touch to the description of the action.

\section{tremare 'shake' vs. tremolare 'shiver'}

We would rather conclude that we have a convergence of morphological and semantic characterisations that strengthen each other. Form and meaning can be said to work hand in hand in providing motivation for this class of verbs and substance to it.

\footnotetext{
${ }^{5}$ To be more precise, number morphology, case marking, transitivity and telicity correlate, see Durie [1986].
} 
We further notice that the process of producing event-internal pluractional verbs, in the sense of association of a form to a meaning, is not very active. For instance, in Italian the sizeable set of diminutive suffixes that was available for verbs is currently shrinking to the triad -acchi/ucchi/icchi- [Grandi 2007], although it remains available in full for the nominal domain. This is to say that verbs like gironzolare 'wander' are no longer created in Italian. In French, the situation is even more clearcut, as diminutive affixation is no longer productive in nominal as well as verbal domains. This situation may suggest to extend to them the status of frozen pluractionals, proposed in the literature for instance for a language like Bole [Schuh and Gimba 2000]. According to Schuh and Gimba [2000], frozen pluractionals are verbs whose unmodified roots are no longer in use and derived forms that do not convey obvious pluractional meaning. The first case is the relevant one for English, for instance. In English, verbs like nibble or sparkle are no longer perceived as morphologically complex. They are no longer perceived as semantically complex either, i.e. involving the modification of several dimensions. They have lost the multiplicative meaning component, e.g. nibble can be used to describe an event of giving a single small bite, and this diminution is the only meaning left. ${ }^{6}$ If the loss of the pluractional flavour is made to correspond with the possibility of restauring the homomorphism between mereological structures of object(s) and event, then the effect of diminution can only be evaluated on the total value of one dimension. This is the situation characterised by a subsective interpretation at the end of section 3.3.1.

Whether the characterisation of frozen form should be applied also to the Italian and French verbs is less clear. On the one hand, it would help us to capture the observation that the morphological contribution may be an artefact. Some forms come from a different origin and have been reanalysed according to a derivational schema in order to be integrated into a paradigm. The status of frozen forms is compatible with a degree of transparency in form or meaning, as in Italian, or with no longer transparent forms, as it seems the case for French and English. On the other hand, it does not fit in well with the fact that the multiplicative interpretation of these verbs cannot be cancelled as a mere implicature, and with the actual (albeit reduced) productivity of the process.

\subsection{On the level of plurality}

As we have seen, a crucial difference between morphologically complex verbs that express event-internal plurality and adverbially modified verbs is that the former always express properties of events modified along at least two dimensions, i.e. increase in frequency and decrease of one or more other dimensions. Thus, the type of word formation by evaluative morphological marking under examination gets direct semantic justification. However, languages may use differential marking or degrees of morphological complexity to express an opposition within Cusic's three level system that is not necessarily the opposition he identified.

Cusic's understanding that languages exploit the same linguistic devices to get a plurality of events and of occasions, is behind his reorganising the system from a three levels hierarchy to the bipartition between event internal vs. event external pluralities that is widely accepted. He supports his claim with English data on the interpretation of adverbials, taken to show that the main opposition is between singularity and plurality at the level of event, and that plurality at the level of occasions is obtained when a second adverbial can support a second

\footnotetext{
${ }^{6}$ Nibble is a semelfactive verb. What is important to underscore is the fact that the 'once only' reading is available in English but not in Italian and French for the morphologically complex forms mordicchiare and mordiller.
} 
distribution. For instance, (18a) says that there are several events and by default we infer that there is one occasion. One reading of sentence (18b) says that there is one event that is repeated at several occasions:

a. The boy shouted again and again

b. Again and again the boy shouted on Tuesday

However, it seems that there are languages that convey number opposition at the interface between event and occasion as themain piece of information. This could be the case in Emerillon, a language of the Tupi-Guarani family, recently discussed by Rose [2007]. Rose matches the morphological opposition between monosyllabic and disyllabic reduplication with the semantic opposition identified by Cusic. More precisely, monosyllabic reduplication of verb forms is said to result in interpretations as event-internal plurality, and disyllabic reduplication to result in interpretations as event-external plurality. However, she needs to invoke ongoing diachronic change to say why this match, presented as typical of the languages of the Tupi-Guarani family, is sometimes blurred in Emerillon. Let us take a closer look at some of her data, starting from disyllabic reduplication. In example (19), we see disyllabic reduplication of the verb, singular subject, and the interpretation is a plurality of events with no strict temporal contiguity.
õhẽ-õ-hem-ne
o-?a
RED-3-sortir-CONTRAST
3-tomber
'Il ressort encore et tombe' (he gets out again and falls)

Now, let's look at monosyllabic reduplication. In example (20), we see monosyllabic reduplication, plural subject, and the interpretation is a plurality of events in strict temporal contiguity or simultaneity.
amõ kito-kom
õ-hẽ-hem
autre grenouille-PL 3-RED-sortir
'Les autres grenouilles sortent' (the other frogs get out)

Example (21), where we see monosyllabic reduplication and plural subject, helps us to check that plural NP need not be taken collectively, since the sentence contains a distributive marker that forces the sequential interpretation. Still, strict temporal contiguity is enforced:
tapig ze-kap1ReR-ne
?i-b
o-po-poR o-ho-n
plouf REFL-derrière-CONTRAST
eau-dans
3-RED-sauter 3-aller-PL
'Elles plongent dans l'eau l'une derrière l'autre' (they dive into the water one after the other)

Finally, in example (22), we see monosyllabic reduplication and singular subject:
ãdudza
wira o-su-su?u
bois 3-RED-mordre
'Le rat a rongé le bois' (the rat nibbled the wood)

It appears that connectedness, one of the parameters of classification used by Cusic in his thesis, is a crucial piece of information. Monosyllabic reduplication matches with strictly contiguous or simultaneous situations, whereas disyllabic reduplication matches with lack of 
temporal contiguity. The data presented by Rose can therefore support the alternative interpretation whereby the main opposition encoded by Emerillon via the two patterns of reduplication is the following. Monosyllabic reduplication correlates with interpretations conveying information on pluralities of events or phases that are all mapped into a single occasion, as if they where necessarily grouped beforehand. Disyllabic reduplication corresponds to interpretations where pluralities of events are distributed over different occasions. Next, monosyllabic reduplication can interact with nominal number to provide further specifications, because nominal number can function as a secondary sorting key. Singular nominal number matches with plurality of phases and plural nominal number matches with plurality of events.

This reanalysis of the Emerillon data embodies an event oriented perspective on the phenomenon and is fully compatible with the idea of the centrality of events in the hierarchy. The original tripartite system set up by Cusic can accommodate it, whereas this is less obvious for the reorganised system, where always talking of repeated actions as event-internal pluralities could turn out to be a bit of a misnomer in Emerillon. Crucial examples are (20) and (21) where the persons who constitute the referent of a plural NP subject execute an action individually and in succession and yet the verb exhibits monosyllabic reduplication. In this type of sentence, the parts of the event hardly qualify as phases, although it may be said that the event is described as a (structured) whole, as expected given the type of reduplication.

Arabic provides another interesting case of potential misalignement with respect to Cusic's event-based bipartition. The relevant interpretative variation is observed with respect to some of the verbs of the second form (the wazn with gemination of the second consonant of the root). Standard Arabic exhibits event-internal pluractionality of the increase type, and verbs of this second form group work as increase pluractionals but they also might distribute over a collective patient. For instance, the verb jarraha, which means to inflict many wounds on a single entity, might distribute over a collective patient and be interpreted as 'wound many' with intensivemeaning but no clear specification that each one element of the collectivity gets many wounds, adapting from [Fassi-Fehri 2003]. This interpretation is possible when the entity realising the theme admits plural interpretation. ${ }^{7}$ This behaviour, in our opinion, has to do with the choices a language make for marking the levels of Cusic's hierarchy. It can be accounted for by making the same assumption adopted for Emerillon, that is that morphological marking via the second form in Arabic does not distinguish between event-internal vs. event-external plurality in the way Cusic has defined, but between plurality of phases and events vs. plurality of occasions. Evidence in support of this analysis comes from the fact that the 'wound many' reading cannot apply to a situation where the wounding of the entities is sparse in time, where sparse in time means that distinct events are mapped onto distinct occasions. This impossibility is not expected if the reading is treated as a case of event-external plurality.

Summing up, in this section we have presented empirical evidence supporting the assumption that the bipartition that Cusic imposes on his three level hierarchy - with pluralities of phases expressed by morphological devices that differ from those used for events and occasions - is just one of the options available to languages. Before we conclude, let us mention the French data in (23) that provide further evidence that a language may use specialised devices to say whether events are distributed or not over occasions.

\section{a. Daniel a sonné deux fois}

\footnotetext{
${ }^{7}$ The same effect, in reverse, can be observed when the English verb massacre is applied to a singular patient.
} 
Daniel rang the bell two times

b. Daniel a sonné à deux reprises

Daniel rang the bell two times

Sentence (23a) is ambiguous between a reading where two ringing events make up a plural event mapped onto one occasion, for instance if Daniel went to the door once and pressed the button twice, and a reading where ringing events are distributed over two occasions, for instance if Daniel went twice to the door and rang the bell. Notice that in this second case, nothing specific is said about the number of ringing events making up each occasion, but this could be added :

(24) Daniel a sonné deux fois à deux reprises

Daniel rang the bell two times twice

On the contrary, sentence (23b) only exhibits a reading where ringing events are distributed over two occasions. The word reprise looks as a classifier specialised for counting events via the occasions they belong to, and not counting events directly.

\section{Concluding remarks}

In this paper, we have pursued the idea that event internal pluractional verbs denote composite single events. Multiplicity of phases is the reflex of a disrupted correlation between a scale/scales measuring a dimension/dimensions and the progression of the event.

The initial question of what is the source of the multiplicative meaning component in verb forms such as tagliuzzare and tossicchiare in Italian, has been answered by arguing that it arises from the use of diminutive morphology in building verb forms that describe noncanonical events. Two semantic operations can be associated with diminutive suffixation, their working in the verbal and nominal domain is similar but the verbal or nominal categories of the outputs open different possibilities.

We have also emphasised that in Romance, although it may be difficult to point to a word formation rule for all cases, morphological form plays a role, since similarity of form triggers pluractional interpretation. A semantic criterion appears to be stronger. We propose that form and meaning together provide motivation for the class of eventinternal pluractional verbs and substance to it.

Finally, we have underscored that in event-internal pluctionality, at least two dimensions of the event are modified and that languages may use morphological distinctions to mark different binary oppositions within Cusic's three level system.

\section{Bibliography}

BAUER Laurie, "The function of word-formation and the inflection-derivation distinction", in AERTSE Henk, HANNAY Mike \& Lyall Rod (eds.), Words in their places. A Festschrift for J. Lachlan Mackenzie, Amsterdam, Vrije Universiteit, 2004: 283-292.

CusIC David, Verbal plurality and aspect, Ph.D. thesis, University of Stanford, 1981.

DowTY David R., Word meaning and Montague grammar, Dordrecht, Reidel, 1979.

DRESSLER Wolfgang, Studien zur verbalen Pluralität, Wien, Österreichische Akademie der Wissenschaft, Phil-Hist, 1968. 
Dressler Wolfgang \& MerLINI BARBARESI Lavinia, Morphopragmatics: diminutive and intensifiers in Italian, German and other languages, Berlin, Mouton de Gruyter, 1994.

DURIE Mark, "The grammaticization of number as a verbal category", Proceedings of the Twelfth Annual Meeting of the Berkeley Linguistics Society, 1986: 355-370.

FASSI-FEHRI Abderkader, "Verbal plurality, transitivity, and causativity", in LECARME Jacqueline (ed.), Research in Afroasiatic Grammar II, Amsterdam, Benjamins, 2003: 151-185.

GRANDI Nicola, "I verbi valutativi in italiano tra azione e aspetto", Studi di Grammatica Italiana XXIV, 2007:153-188.

JURAFSKY Dan, "Universal tendencies in the semantics of the diminutive", Language 72, 1996: 533-578.

KRIFKA Manfred, "The origins of telicity", in RoTHSTEIN Susan (ed.), Events and Grammar, Dordrecht, Kluwer, 1998: 197-235.

LANDMAN Fred, Structures for semantics, Studies in Linguistics and Philosophy, Dordrecht, Kluwer Academic Publishers, 1991.

LANDMAN Fred, Events and plurality, Dordrecht, Kluwer Academic Press, 2000.

LINK Godehard, "The logic analysis of plural and mass terms: a lattice theoretical approach", in BÄUERLE Rainer, SchwARZE Christoph \& vON Stechow Arnim (eds.), Meaning, Use and Interpretation of Language, de Gruyter, 1983: 302-323.

Lo DuCA Maria, "Derivazione nominale deverbale. Nomi di strumento", in GrossmanN Maria \& RAINER Franz (eds.), La formazione delle parole in italiano, Tubingen, Niemeyer, 2004: 227-233.

Merlini BARbARESI Lavinia, "Alterazione", in Grossmann Maria \& RAINER Franz (eds.), La formazione delle parole in italiano, Tübingen, Niemeyer, 2004: 264-292.

MonTAgue Richard, "English as a formal language", in THOMASON Richmond H. (ed.), Formal philosophy, New Haven, Yale University Press, 1974: 188-221.

NeWman Paul, The classification of Chadic within Afroasiatic, Leiden, Universitaire Pers, 1980.

RoSE Françoise, "Action répétitive et action répétée: aspect et pluralité verbale dans la réduplication en émérillon", Faits de langues 29, 2007: 125-143.

SCALISE Sergio, Generative Morphology, Dordrecht, Foris, 1984.

SchUH R. G. \& GiMbA A. M., A grammar of Bole, ms. USC and University of Mojimbo, 2000.

SIEGEL Muffy, Capturing the adjective, Ph.D. thesis, University of Massachussets at Amherst, 1976.

STUMP Greg, "How peculiar is evaluative morphology", Journal of linguistics 29, 1993: 1-36.

TenNy Carol, Aspectual roles and the syntax-semantics interface, Dordrecht, Kluwer Academic Publishers, 1994.

ThORNTON Anna M., "Italian reduplicated imperatives as instances of verbal plurality", talk, Pluralité nominale et verbale, Paris 9-10 November 2007.

TovenA Lucia M., "A class of pluractional verbs in Italian and French", handout, Semantics beyond set theory, Paris 25 October 2007.

Tovena Lucia M., "Pluractional verbs that grammaticise number through the part-of relation", in KAMPERS-MANHE Brigitte, BOK-BENNEMA Reineke \& HOLLEBRANDSE Bart (eds.), Romance Languages and Linguistic Theory 2008, Amsterdam, John Benjamins, 2010a.

Tovena Lucia M., "Pluractionality and the unity of the event", in AlOni Maria \& Schulz Katrin (eds.), Amsterdam Colloquium 2009, Heidelberg, Springer, 2010b: 465-473.

TovenA Lucia M., "The imperfect measure of internally plural events", in BeZHANISHVILI 
Nikoloz, Loebner Sebastian, Schwabe Kerstin \& Spada Luca (eds.), Logic, Language and Computation, Eighth Tbilisi Symposium, Heidelberg, Springer, 2010c.

Tovena Lucia M. \& Donazzan M., "On ways of repeating", Recherches Linguistiques de Vincennes 37, Thematic issue, TOVENA Lucia (ed.), Aspect et pluralité d'événements, 2008: 85-112. 